\title{
Zhangjiajie's Current Tourism Economy-Vision of Tourism Industry and Solutions for Development
}

\author{
Wen Zhou ${ }^{1,2, a}$, Xuebin Huang ${ }^{1, b}$, Jia Zhu ${ }^{3, c}$ and Kun Zhang ${ }^{1, d^{*}}$ \\ ${ }^{1}$ Education Center of MTA, Hainan Tropical Ocean University, Sanya, Hainan, 572022, China \\ ${ }^{2}$ Department of Tourism Management, Zhangjiajie Institute of Aeronautical Engineering, Zhangjiajie, \\ Hunan, 427000, China \\ ${ }^{3}$ Art College of Hainan Tropical Ocean University, Hainan Sanya 572022, China \\ a zhouwen1128@163.com, bpu.huang@qq.com, 'zhujia1217@126.com, dzk0588@163.com \\ The corresponding author
}

Keywords: Zhangjiajie; Tourism planning; Economic development

\begin{abstract}
Zhangjiajie is a tourist city with tourism as the main economic industry, with rich tourism resources and favorable geographical advantages. This paper analyzes the development of Zhangjiajie tourism scenic spot, points out the problems existing in the development of Zhangjiajie tourist area, and puts forward the countermeasures of rationalization.
\end{abstract}

\section{Introduction}

Zhangjiajie is located in north-west Hunan province and has the common boundary with Hefeng County in the north. With covering area of 9518 square kilometer and total population of 1623.9 thousand people, Zhangjiajie administered two districts and two counties-Yongding district (municipal district), Wulingyuan district (scenic spot), Cili County and Sangzhi County in 2010. Located in upper and middle reach of the Lishui River (in Hunan Province), Zhangjiajie could be hinterland of Wuling Mountain and is one of important tourism cities.In September1982, Zhangjiajie was listed as the first one of China's national forest park, in August 1988, Wulingyuan was listed into second batch of 40 key scenic spots; In 1992, natural scenic spot in Wulingyuan was listed into List of World Natural Heritage Sites by UNESCO covering Zhangjiajie National Forest Park, Scenic Spot of Suoxi Valley and Scenic Spot of Tianzi Mountain. All facts proved that Zhangjiajie is tourism city with rich and abundant tourism resources, which bring substantial economic profits to Zhangjiajie since tourism industry was developed,therefore, it is necessary to research scenic spot in Zhangjiajie.

\section{Current Situation of Economic Development for Tourism Industry in Zhangjiajie}

Brief Introduction of Tourism Resources in Zhangjiajie. Locating in north-and-west Hunan province, Zhangjiajie is prefecture-level city with governance of Hunan province, established in 1988, this city was renamed Zhangjiajie from original name of Dayong in April 1994, Zhangjiajie was listed into Top 200 China's Attractive Cities in 2012. The major scenic spots in municipal Zhangjiajie covers a wide range: Drifting On MaoYan River in Yongding Area, Badagong Mountain, scenic spots in Wuling Area, Jiutian Cave in Sangzhi County, Tianmen Mountain, Jade Emperor Grotto, Jiangya Hot Spring, Wulei Mountain in Cili County and Puguang Temple. Red tourism resources has He Long's hometown, place of departure for long march of the Second Front Red Army, Old District of Provincial Military Command. 12 state-level scenic spots has been built in the whole city, referring to two 5A-level scenic spots and two 4A-level scenic spots, thus leading to strong capacity of reception. 
Currently Economic Situation of Tourism Industry in Zhangjiajie. In recent years, the scale of tourism industry has been expanded with double growth of tourists and incomes in Zhangjiajie, thus constituting the solid foundation for leading role in national economy. There are 12 state-level scenic spots in the whole city, referring to two 5A-level scenic spots and two 4A-level scenic spots.35.901million tourist are treated in scenic spots in the whole year, increasing 18\%, among whom 14.8505 billion tourists are overnight visitors, increasing $11.5 \%$. Thus achieving the total incomes up to 20.872 billion yuan in tourism, increasing $24.7 \%$. These incomes are composed of 1.838 billion yuan from gate receipts with $12.1 \%$ increase and 0.366 billion dollar of foreign currency earnings with $21.2 \%$ increase. There are 14 state-level scenic spots in the whole city in 2013, referring to two more than 5A-level scenic spots and two more than 4A-level scenic spots. There are 898 hotels in which 48 are star-level hotels. There are 63. 6thousand beds in hotels in which 13 thousand bed is star-level hotel. There are 62 travel agencies and 4875 people with tourist certificate among whom 568 are foreign-language tour guides.34.4241 million tourists are treated in the scenic spot for the whole year, dropping 4.1\%.14.25 million overnight tourists are treated, dropping 4\%, which shows that 2.0658 million tourist are foreign visitors, dropping $4.3 \%$. The total incomes of tourism in the whole city reaches to 21.2 billion yuan, increasing $1.7 \%$, which shows that gate receipts is 1.756 billion yuan in falling $4.5 \%$ and foreign currency earnings 0.327 dollars in falling $10.7 \%$. What has succeeded in treating 38.84 million tourists in which there are 16.44 million visitors and earning total tourism incomes up to 24.6 billion yuan, grew $12 \%, 16 \%$ and $16 \%$ on year-on-year basis.

According to national ecological footprint from wackernagel's calculation, the EOI seemed to be $45.58 \%$ in average (see table12) in typical countries with comparatively developed ecological resources and tourism industry in 1977. The EOI in Zhangjiajie is $0.021 / 0.04=0.53$, slightly higher than other nine countries in average in 2010, which could indicates that the sustainable degree of tourism in Zhangjiajie is not very high but in average level.

Table 1 Ecological occupancy index of tourism for Zhangjiajie in 2010

\begin{tabular}{cccc}
\hline Countries & Eco-tourist footprint & Ecological carrying capacity & EOI $(\%)$ \\
\hline Brazil & 3.8 & 9.1 & 41.75 \\
Finland & 2.4 & 5.0 & 48.00 \\
Iceland & 6.4 & 9.8 & 65.31 \\
Peru & 8.2 & 26.8 & 30.60 \\
New Zealand & 1.4 & 2.7 & 51.85 \\
Australia & 10 & 16.3 & 61.35 \\
Columbi & 7.4 & 12.6 & 58.73 \\
Indonesia & 6.6 & 21.8 & 30.27 \\
Average & 1.7 & 7.6 & 45.58 \\
Zhangjiajie & 0.021 & 0.040 & 53.31 \\
\hline
\end{tabular}

Note: besides Zhangjiajie, the EOI seemed to be for other countries in 1977.

With a view to what has been mentioned, conducting comparison with countries with internationally-accepted quality of ecological environment and developed tourism industries could better explain the relationship between tourism EOI and sustainable development of tourism so as to judge the sustainable situation of regional tourism with comparative analysis with internationally-accepted countries. Which could conclude the conclusion that the comprehensively economic level of tourism in Zhangjiajie plays the leading role domestically and could be qualified to a certain extent as well as middle level globally, therefore the sustainable, comprehensive and humanity ideas lack something and will need to supply something to a certain extent. 


\section{Constraints on Economic Development of Tourism in Zhangjiajie}

Frequent Occurrence of Natural Disaster in Scenic Spot. The land form of sandstone peak leads to weak ecological environment of tourism scenic spot in Zhangjiajie, which is evolved from terrace, mesa, peak wall, peak cluster, peak forest, remnant forest to denuded ground. The cliffs become very dangerous under the blazing sun for quite a long time and heavy rain so that such geological events could happen as rock avalanche and cliff fall at any time. The rocks were loose and collapsed from high elevation as result of rainstorm in 2004 so as to bring three tourists to death. The dangerous natural disasters happen frequently due to chaotic strata structures, high mountain and risky slopes as well as heavy rain in this complex terrain of Zhangjiajie.

Simple Structure of Tourism Product and Blurred Brand Image. The diversity of tourism products could lay the solid foundation for tourism development, but with the rapid development of tourism for many years, the supply of tourism products in Zhangjiajie still remains very single with weak products development. The tourism in Zhangjiajie considers natural elements of mountain, water, cave and forest as major starting point for tourism resources, values development about tourist attraction of tourism products and single-way landscape without combination of other forms of travel function as well as in-depth development of more tourism product assortment, such advantages fail to fully best use covering red tourism, the intangible culture and tourism resources of folk custom as result of fewer tourism product, simple types and poor supply.

There is poor recognition of implied value of tourism resources in Zhangjiajie for a long period so as to lack efficient propaganda as well as clear operation and management system against uncertainties in selling point of tourism promotion, thus leading to tourism brand with blurred bounds among mountain, water, folk custom and humanities. There are bugs existing in propaganda system of tourism brand so as to fail to integrated system lasting for a long time with weak promotion and loose brand publicity as well as product promotion and even mutual attacks among brands; Vicious competitions bring out among each other relying on external marketing of travel agency. All result in chaotic management of tourism brands in Zhangjiajie.

\section{Suggestions for Promoting Development of Tourist Area in Zhangjiajie}

Strengthening Research on Protecting Natural Landscape. The research force should be organized to establish expert panel on protection of Zhangjiajie scenic spots or association, the government should play the leading role in investing capital to establish regular research organization, which should carry out active research and apply the results to actual governance so as to bring about virtuous circle between research and governance.

Optimizing Tourism Product Structure in Scenic Spot. When it comes to rapid change of tourist demands, guided by tourists, the tourism enterprises in Zhangjiajie should timely establish efficient marketing and communication strategy for tourist demands to quickly respond to market opportunity. Every tourist or one kind of tourists has their differently own needs as well as relevant communication way, which needs changes of individuality and communication as well as social environment.

Forming Brand Features of Tourism Itself in Zhangjiajie. Red tourism brand. Rich tourism resource could be the highlights in Zhangjiajie scenic spots, for example He Long's home town, the development of red tourism should be valued in developing tourism resources in Zhangjiajie scenic spots. In addition, in order to do a good job in product development of red tourism in Zhangjiajie, we should start from brand design and promotion to turn red tourism resources into windows of cultural and ideological progress, spotlights of cultural industry and educational base of patriotism. Investment should be increased on mature red tourism products and improvement of tourism facilities and equipment. 
Tourism brand of sports competition. The tourism industry with beautiful landscape should be organically combined with exciting and interesting athletic contests based on unique advantages, for example national competition in Lishui River and rock climbing competition. These efforts make sports competition appear in tourism vision to strengthen tourism functions of competition, which could better satisfy people's needs for culture and entertainment to enlarge and give full play to social and economic functions of sports competition as well as reach the end about protecting environment.

Various health care tourism. The health care tourism mainly focuses on nature in Zhangjiajie among ranges of nature and humanities. Which boasts a wide ranges of forests-health care tourism resources, village tourism resources and waterfront health care tourism resources, while forests-health care tourism resources cover forests and lofty mountains which has been evolved into one of important advantages about tourism resources in Zhangjiajie and health care tourism resources, namely first national forest parks and national level-5A tourist attraction are Zhangjiajie national forest park and Tianmen national forest park respectively, in addition, Zhangjiajie boasts vast land of forest resources where rich forest tourism resources could forest bath and healthy pathway.

Colorful village folk customs and interesting village cultural arts are important parts of village culture in Zhangjiajie. Residents live in a compact community to bring unique charm to villages in Zhangjiajie, especially medical skill of the Miao minority, the Miao doctors create system of their own with long history, both old and profound, known to home and at abroad as result of treating an internal illness by external treatment in particular, thus resulting in in-depth research on health care for the aged, Zhangjiajie carries forward medical skills of the Miao minority in the period of developing village health care tourism so as to provide medical resources for health care of the aged.

\section{Summary}

Like other typical tourist cities, tourism, as the main urban industry in Zhangjiajie, is the main factor of Zhangjiajie economy. In the modern tourism industry, Zhangjiajie must change its original pattern and find its own deficiencies. Characteristics, adapt to the times, play a unique resource advantages, the formation of sustainable economic development of tourism economy model system, is a good line.

\section{Acknowledgement}

This research was financially supported by the Hainan Province Tourism Management Key Disciplines Construction Project; the MTA Teaching Reform Research Project (No. MTAJG2016-07); the Hainan Planning Projects of Philosophy and Social Sciences (No.HNSK (QN) 15-60); the Scientific and Sechnological Cooperative Project for College and Region of Sanya (No.2014YD36); the 2016 Hainan Education Science Study Topics of the "13th Five-Year" Plan (No.QJY13516030).

\section{References}

[1] Zhaofeng Wang, Han Yu, Research on the Coupling Development of China's Tourism Development and Small Town Construction, Economic Geography, No.07, pp.165-171, 2016.

[2] Xuefeng Ma, Gennian Sun, The SGGT Model and Spatial Evolution of the Growth Point of Tourism Industry - Taking Zhangjiajie as an Example, Geographical Research, Vol.35, No.10, pp. 1923-1936, 2013.

[3] Nianfeng Liu, Reizhen Yao, Rui Liu, Weiwei Song, Based on EFA in Ecological Carrying Capacity and Sustainable Development of Tourist, Environmental Science \& Technology, Vol.28, No.05, pp. 95-97, 2005. 
[4] Wen Zhou, Hui Xie, Marketing Strategy Analysis of Zhangjiajie Tourist, Global City Geography, No.16, pp.226, 2016.

[5] Minsheng Liao Kun Zhang, Hongxu Wang, Zhuang LI, Haifeng WANG, Research on Forecasting the Quantity of Tourists in Sanya City, Economic Research Guide, No.01, pp.239-243, 2015.

[6] Kun Zhang, Hong-Xu Wang, Hai-Feng Wang and Zhuang Li, The Time Series Prediction Algorithm of Enrollment based on the Hesitancy degree Correction Rule of Vague Sets, ICIC Express Letters. 2015, Vol.09, No.05, pp.1311-1318.

[7] Minsheng Liao, Kun Zhang, Hongxu Wang, Zhuang LI, Haifeng Wang, Forecasting Total Tourism Income of Sanya Based on Fuzzy Time Series Model, Economic Research Guide , No.04, pp.237-242, 2015.

[8] Xiaolan Lei, Based on the Landscape Index and the Ecological Footprint of Pingtan Island Ecological Carrying Capacity Study, Journal of Fujian Normal University(Natural Science Edition), Vol.33 No.01, pp.75-81, 2017.

[9] Yuguang Chang, Chunqin C Chang, Haipeng Niu, Tourismsite ECC of Yuntaimountain Based on Analytic Hierarchy Proces, Journal of Henan Polytechnic University(Natural Science), Vol.27, No.02, pp.188-192, 2008.

[10]Hui Wang, Jianguo Lin, Calculation of Tourism Environmental Carrying Capacity on Tourist Ecological Footprint Model, Journal of Dalian Maritime University, Vol.31, No.03, pp.57-61, 2005. 